\title{
Políticas de inclusão no ensino superior: avaliação do desempenho dos alunos baseado no Enade de 2012 a 2014'
}

Jacques Wainer"

Tatiana Melguizo III

\section{Resumo}

Este artigo compara as notas obtidas nos Enades de 2012 a 2014 por alunos que entraram no ensino superior via cotas, receberam bolsa ProUni ou empréstimo via Fies com a nota de seus colegas de classe que não receberam o benefício correspondente. A comparação é feita usando a diferença entre as médias das notas padronizadas dos exames gerais e específicos do Enade. 0 artigo define um limite de equivalência como sendo a diferença da média das notas dos 5\% dos alunos com resultados logo acima da média e dos 5\% dos alunos logo abaixo da média de todos os alunos. Diferenças abaixo desse valor foram consideradas sem importância prática. Tendo em vista essa definição, alunos cotistas tiveram desempenho equivalente ao de seus colegas de classe não cotistas, assim como os alunos que recebem empréstimo do Fies. Alunos que recebem bolsa do ProUni tiveram desempenho superior ao dos seus colegas de classe.

\section{Palavras-chave}

Educação superior - Cotas - ProUni - Fies - Enade - Desempenho.

I- Agradecimentos: a pesquisa reportada neste artigo foi financiada pelo projeto Fapesp 15/19288-0.

II- Instituto de Computação. Universidade de Campinas (Unicamp), Campinas, SP, Brasil.

Contato: wainer@ic.unicamp.br

III- Rossier School of Education. University of Southern California. Los Angeles, CA, EUA. Contato: melguizo@usc.edu 


\title{
Inclusion policies in higher education: evaluation of student performance based on the Enade from 2012 to 2014
}

Jacques Wainer"

Tatiana Melguizo"II

\begin{abstract}
This paper compares the grades on the Enade exams from 2012 to 2014 of students who were accepted into higher education through affirmative action, who received the ProUni scholarship, or who received the government sponsored student loans (FIES) with the grades of students in the same class who did not receive the corresponding benefit. The mean of the standardized exam grades (both general and specific exams) are used for the comparison. The paper defines a limit of equivalence between grades as the difference of the mean grade of the 5\% students with grades just above the mean and of the 5\% students with grades just below the mean of all students. Differences below this limit of equivalence are considered of no practical relevance. Under this definition, the performance of students who were accepted through affirmative action is equivalent to that of their classmates who did not receive such benefit, as is the performance of students who received the FIES student loan. Students who received the ProUni scholarship performed better than their classmates.
\end{abstract}

\section{Keywords}

Higher education - Affirmative action - ProUni - FIES - Enade - Performance

I- Acknowledgment: this research was funded by FAPESP grant 15/19288.

II- Instituto de Computação. Universidade de Campinas (Unicamp), Campinas, SP, Brasil.

Contato: wainer@ic.unicamp.br

III- Rossier School of Education. University

of Southern California. Los Angeles, CA, EUA.

Contato: melguizo@usc.edu 


\section{Introdução}

Há três famílias de ações de inclusão no ensino superior (ES). A primeira é a política de cotas, ou política de ação afırmativa, que reserva vagas de Instituições de Ensino Superior (IES) para alunos de grupos desprivilegiados (seja por critério de raça ou social). A segunda é uma política de bolsas para alunos de grupos desprivilegiados, e a terceira, uma política de empréstimo para o pagamento das mensalidades em IES pagas.

As políticas de cotas atingem principalmente IES federais e estaduais, que na sua maioria, reservam vagas para alunos de grupos desprivilegiados. Em poucos casos, alunos dos grupos desprivilegiados recebem um bônus na pontuação do vestibular. As políticas de cotas surgiram em 2000 nas universidades estaduais, em particular UERJ e UENF (Universidade Estadual do Norte Fluminense). A partir de então, IES estaduais e federais passaram a crescentemente incluir políticas de cotas, com critérios diferentes, baseados em leis estaduais ou decisões dos respectivos conselhos universitários (FERES JÚNIOR; DAFLON, 2014; EURÍSTENES; CAMPOS; FERES JÚNIOR, 2015).

Um marco fundamental para as políticas de cotas foi a aprovação da Lei 12.711/2012. A lei impõe um programa crescente de cotas em todas as universidades e institutos federais até atingir, em 2016, o patamar de 50\% das vagas de todos os cursos dedicadas a cotas, e uniformiza os critérios para sua distribuição. A lei impõe que:

- no mínimo 25\% das vagas sejam preenchidas por estudantes de escolas públicas e com renda bruta de até 1,5 salários mínimos;

- um percentual apropriado dessas vagas seja alocado para alunos pretos, pardos e indígenas, que deve corresponder à proporção de pessoas dessas etnias/raças no estado;

- até $25 \%$ das vagas sejam ocupadas por estudantes de escolas públicas com renda superior a 1,5 salários mínimos;

- um porcentual apropriado dessas vagas seja preenchido por alunos pretos, pardos e indígenas.
Há alguns programas federias de bolsas e auxílios, mas o mais famoso é o Programa Universidade para Todos (ProUni) que dá bolsas para o pagamento das mensalidades de alunos em IES pagas (as bolsas cobrem 100\% ou 50\% da mensalidade). Existem também alguns programas federais de bolsas e auxílio para ajuda de custo: associado ao ProUni existe o Programa Bolsa Permanência, que dá um auxílio no valor de uma bolsa de iniciação científıca para alunos com bolsa integral do ProUni. Há também o Programa de Bolsa Permanência (PBP), que dá bolsas para alunos indígenas ou em vulnerabilidade socioeconômica que estão cursando IES federais. Bolsas de manutenção e permanência, auxílios e ajudas de custo não serão objetos deste estudo.

Finalmente, o mais conhecido programa dentro da terceira família é o Fundo de Financiamento Estudantil (Fies). Alunos recebem um empréstimo para pagar as mensalidades da instituição e começam a pagar o empréstimo um ano após a conclusão do curso. Até 2015, a taxa de juros do Fies era de 3,4\%, e a partir de 2015, de $6,5 \%$. Como as taxas de juros são efetivamente menores que a inflação, pode-se considerar que o Fies é um programa de transferência de recursos para as famílias de alunos com maior vulnerabilidade econômica.

0 objetivo deste artigo é analisar se, ao final do curso, o rendimento dos alunos que se beneficiaram de qualquer uma dessas três variações de programas de inclusão (cotas, ProUni ou empréstimo) é equivalente ou não ao de seus colegas que não se beneficiaram dessas políticas. Para tanto, usaremos dados do Enade de 2012, 2013 e 2014. 0 Enade é um exame para alunos que estão concluindo um curso superior e contém duas partes: uma geral, comum para todos os alunos de um determinado ano, que mede habilidades cognitivas gerias, tais como interpretação de textos e gráficos, raciocínio lógico etc.; e a parte específica, que mede conhecimentos particulares de cada curso.

De forma geral, a ideia desta pesquisa é sempre comparar dois grupos: os alunos 
que se beneficiaram de alguma das políticas de inclusão discutidas acima e seus colegas de classe que não se beneficiaram delas. "Classe", neste artigo, é uma combinação única de IES, curso, período das aulas e município - todos os alunos do curso A, no período noturno, da IES B, na cidade $C$ são considerados colegas de classe. Assim, por exemplo, se estamos comparando o rendimento de alunos que se beneficiaram de políticas de cotas (sejam sociais ou raciais), então faremos a comparação de todos os alunos cotistas nos três anos analisados, com os demais alunos das classes em que os cotistas cursaram seu ensino superior. E compararemos os dois grupos usando tanto as notas dos exames específicos como as notas dos exames gerais. Discutiremos, na seção metodologia, que é possível combinar os resultados dos exames de diferentes cursos/carreiras num só resultado.

Dessa forma, os objetivos deste trabalho são determinar se:

- estudantes cotistas (tanto por razões sociais quanto raciais) têm um desempenho nos exames do Enade equivalente ou não ao dos seus colegas de classe não cotistas;

- estudantes que recebem bolsas do ProUni têm desempenho equivalente ou não ao dos seus colegas que não receberam a bolsa;

- estudantes que receberam empréstimo do Fies têm um desempenho equivalente ou não ao dos seus colegas que não receberam o empréstimo.

Acreditamos que as respostas a essas questões são importantes na avaliação das políticas de inclusão no ensino superior. Dessa forma, achamos importante não discutir, por exemplo, diferenças de desempenho entre diferentes cursos, como tem sido feito na grande maioria das publicações sobre o assunto.

\section{Avaliação de programas de inclusão}

Há quatro dimensões a partir das quais um programa de inclusão em ES pode ser avaliado. A primeira delas é o acesso à educação superior. Espera-se que uma maior diversidade de alunos passe a frequentar o ES em relação ao que se esperaria sem essas políticas de inclusão. A segunda e terceira dimensões são evasão e tempo para a graduação. Alunos cotistas e potencialmente alunos bolsistas provavelmente têm piores condições socioeconômicas e educacionais para cursar o ES. Dificuldades financeiras para pagar as mensalidades e para se sustentar durante o ES e uma pior formação no ensino secundário podem forçar alunos cotistas e bolsistas a abandonar o ensino superior (aumentando a evasão), ou, no mínimo, atrasar a conclusão dos cursos (aumentando o tempo para graduação) em comparação a seus colegas não cotistas e não bolsistas. Embora essas dimensões sejam importantes, este artigo não tratará delas. Finalmente, a quarta dimensão é o rendimento dos alunos: alunos bolsistas e cotistas se formam com o mesmo nível de conhecimento que seus colegas? Esse é o foco deste artigo.

Há alguns artigos científicos sobre o ProUni, mas a maioria são pesquisas qualitativas sobre as opiniões e experiências dos bolsistas (AMARAL; OLIVEIRA, 2011; SARAIVA; NUNES, 2011; CARVALHO, 2008). Almeida et al. (2010) inclui um levantamento de testes e dissertações sobre o ProUni até 2009. 0 único artigo sobre políticas de financiamento e rendimento dos alunos é o de Barbosa e Santos (2011). As autoras usam dados do Enade e comparam as notas no exame de alunos com e sem bolsa ProUni, e com e sem empréstimo do Fies, em oito cursos diferentes. Com poucas exceções, alunos com bolsa do ProUni têm melhores notas nos exames e, em três dos cursos, alunos com empréstimos do Fies têm notas maiores que os alunos sem nenhuma bolsa ou auxílio. As autoras não fazem a análise de significância estatística para as diferenças encontradas.

A política de cotas recebeu muito mais atenção no debate público, seja em artigos científicos, seja em debates. A grande maioria de artigos científicos sobre a política de cotas inclui dados sobre acesso, evasão e rendimento 
de cotistas em relação a não cotistas. A grande maioria dessas pesquisas usa dados privilegiados de uma IES em particular. Nesses casos, os pesquisadores têm acesso às notas das várias disciplinas de alunos cotistas e não cotistas e comparam uma média ponderada das notas (que algumas IES chamam de coeficiente de rendimento - CR - nome que usaremos neste artigo) dos dois grupos. A maior parte dos artigos sobre rendimento tem algumas características e limitações metodológicas em comum (as exceções serão destacadas mais adiante):

- Os dados são separados por cursos/ carreiras. Normalmente os autores separam os cursos num grupo de maior prestígio, ou maior concorrência no vestibular, e o grupo de menor prestígio. A análise é feita separadamente para cada curso e não há uma forma de agregar os dados, a não ser contando o número de cursos nos quais há ou não diferença nos $\mathrm{CR}$ de cotistas e não cotistas.

- $0 \mathrm{CR}$ utilizado na análise não é o $\mathrm{CR}$ dos alunos ao final do curso, mas em algum momento durante curso. Dessa forma, a análise não reflete a diferença (ou não diferença) do rendimento dos alunos quando se formam, mas um ou dois anos após iniciarem o ES.

- Não são feitos testes estatísticos, assim não é possível dizer se a diferença é ou não estatisticamente significativa, ou seja, se a diferença na média dos CRs pode ser atribuída apenas à sorte (ou, mais formalmente, a erros amostrais).

- Os artigos trazem afırmações de que as diferenças não são importantes ou que as médias dos CR são equivalentes sem uma definição explícita do que sejam diferenças importantes ou limites de equivalência.

Abaixo descrevemos brevemente as principais publicações nacionais sobre rendimento de cotistas.

Universidade de Brasília (UnB) Velloso (2009) analisa alunos ingressantes de 2004 a 2006 em todos os cursos. Diferente da maioria dos artigos, esse estudo define que uma diferença de 5\% na média dos CR dos dois grupos não é expressiva. 0 autor conclui que para dois terços das turmas (combinação de curso e ano) não há "diferenças expressivas entre as médias dos dois grupos ou estas foram favoráveis aos cotistas" (VELLOSO, 2009, p. 621). Garcia e Jesus (2015) analisam os CR de alunos ingressantes de 2004 a 2012, semestre a semestre, em nove cursos. Diferente da grande maioria dos outros artigos, esse estudo usa testes estatísticos para verificar se as diferenças entre o CR de cotistas e o de não cotistas em um semestre são estatisticamente significativas. Os autores definem que cotistas e não cotistas têm CR equivalentes ao longo de um curso se, em pelo menos 50\% dos semestres do curso, as diferenças entre cotistas e não cotistas não sejam estatisticamente significativas. Dada essa definição, em cinco dos nove cursos, cotistas e não cotistas tiveram $\mathrm{CR}$ equivalentes.

Universidade Federal da Bahia (UFBA) - Queiroz e Santos (2006) analisaram os alunos ingressantes em 2005 após dois semestres. Os autores computaram a proporção dos alunos (cotistas e não cotistas) que tiveram um CR acima de 5,1 nos dezoito cursos de maior concorrência. Em 61\% dos cursos, a proporção dos cotistas com CR acima de 5,1 foi maior ou igual à proporção equivalente dos não cotistas. Santos e Queiroz (2013) estenderam a análise para alunos ingressantes em 2006, cursando o sétimo semestre nos dezoito cursos. Os resultados foram similares aos reportados no artigo anterior.

Universidade Estadual do Rio de Janeiro (UERJ) - Pinto (2006) comenta que existem duas pesquisas divulgadas pela UERJ com resultados contraditórios, uma mostrando que alunos cotistas tinham resultados equivalentes ao de não cotistas, e outra mostrando que o resultado era pior. Bezerra e Gurgel (2011, p. 12) comparam o CR de ingressantes em 2005 e 2006 para seis cursos e concluem que a "diferença se reduz a quase nada”. Mendes Junior (2014) analisa os CRs em 2006 e 2009 e o CR final de alunos ingressantes em 2005. Nos três períodos, o CR médio de alunos não cotistas é maior que 
o de alunos cotistas em 6,57\%, 6,72\% e 8,5\%, na média para todos os cursos.

Tessler (2006) mostra que, no terceiro semestre, alunos beneficiados por ações afirmativas da Unicamp tinham notas maiores que seus colegas em 56\% dos cursos, e que essa diferença era estatisticamente significativa (a Unicamp dá uma bonificação nos pontos do vestibular em vez de reservar vagas para alunos que se beneficiam das políticas de inclusão). Silva e Pacheco (2013) apresentam dados de distribuição de alunos cotistas, rendimento dos mesmos em cursos de alta e baixa concorrência e suas taxas de evasão e de reprovação na Universidade Estadual de Londrina. Beraldo e Magrone (2013) apresentam dados sobre evasão e rendimento de cotistas da Universidade Federal de Juiz de Fora, e Neves (2013) apresenta dados sobre evasão, repetência e rendimento de alunos cotistas e não cotistas da Universidade Federal de Sergipe. Não é fácil sumarizar os resultados desses trabalhos, pois as análises são geralmente separadas por curso e ano (e também por tipo de ação afırmativa). Portanto, não há uma conclusão única que resuma os resultados.

Artigos sobre cotas que usam dados do Enade, como é o caso da presente pesquisa, são poucos. Waltenberg e Carvalho (2012) usaram dados da prova específica do Enade 2008 e encontram uma diminuição de quatro pontos (sobre um máximo de cem) nas notas dos alunos cotistas de universidades federais e estaduais. A diferença é estatisticamente significativa. Nas IES privadas a diferença não é significativa. Os autores também criaram modelos de regressão que levam em consideração a situação socioeconômica do aluno, mas, mesmo assim, encontram um desempenho mais baixo para alunos cotistas em IES públicas de todas as áreas, enquanto que em IES privadas a diferença de rendimento se faz presente apenas em cursos de maior prestígio social. Pereira, Bittencourt e Braga (2015) usam um modelo de diferenças-em-diferenças e propensity score matching para calcular o efeito de alunos cotistas no Enade de 2008. Os autores concluem que os alunos cotistas tiveram um impacto negativo (e estatisticamente significativo) nos cursos de pedagogia, história e física, e tiveram um impacto positivo (e estatisticamente significativo) no curso de agronomia. Gutterres (2015) usa os dados da prova geral do Enade de 2012 e compara cotistas por razão de terem feito segundo grau em escola pública, por raça e por renda familiar. 0 autor encontra diferenças a favor de cotistas que entraram por razão de terem feito escola pública.

\section{Dados e Metodologia}

\section{Dados}

Esta pesquisa usa dados do Enade de 2012, 2013 e 2014. 0 exame de 2012 cobre dezessete cursos na área de Ciências Sociais Aplicadas e seis cursos superiores de tecnologia. 0 de 2013 cobre dezessete cursos da área de Ciências da Saúde e quatro cursos de tecnologia. E, finalmente, o Enade de 2014 cobre 43 cursos, a maioria da área de Engenharias e Ciências Exatas, mas também áreas como Filosofia, História, Letras etc. e quatro cursos de tecnologia.

Foram eliminados os dados de alunos que não participaram efetivamente do exame (variável tp_pres nos dados do Enade) e daqueles que não preencheram os campos de resposta relativo à entrada no ES por meio ou não de cotas, ou se receberam bolsa. A medida de desempenho específico é a nota total na parte específica do Enade (nt_ce), e a medida de desempenho geral é a nota total na parte geral do exame (nt_fg).

A questão se o aluno entrou no ES por meio de cotas possui uma ambiguidade. As respostas nos três questionários são: a) Não entrou via o sistema de cotas; b) Sim, por critério étnico-racial; c) Sim, por critério de renda; d) Sim, por ter estudado em escola pública ou particular com bolsa de estudos; e) Sim, por sistema que combina dois ou mais critérios anteriores; f) Sim, por sistema diferente dos anteriores.

Consideramos que a resposta b) indica que o aluno entrou no ES pelo sistema de cotas 
raciais, e as respostas c) e d) indicam cotas por critérios sociais. Mas a resposta e) pode indicar tanto que o aluno combinou os dois critérios sociais (baixa renda e ter estudado em escola pública) ou um critério social com um racial (aluno pardo que estudou em escola pública). Como não foi possível distinguir entre essas alternativas, fizemos duas análises separadas: uma em que o critério racial não inclui os alunos que responderam a alternativa e), e outra em que o critério racial inclui todos os alunos que escolheram as alternativas b) ou e). Similar procedimento foi adotado para o critério social: inclui apenas as alternativas c) e d) ou c), d) e e).

Consideramos que os alunos que receberam bolsa integral ou parcial pelo ProUni, ou bolsa parcial mais o Fies.

Tabela 1 - Quantidade de alunos em cada grupo

\begin{tabular}{|c|c|c|c|c|c|c|c|c|}
\hline & \multicolumn{2}{|c|}{2012} & \multicolumn{2}{|c|}{2013} & \multicolumn{2}{|c|}{2014} & \multicolumn{2}{|c|}{ Total } \\
\hline Dados originais & \multicolumn{2}{|c|}{469.460} & \multicolumn{2}{|c|}{167.787} & \multicolumn{2}{|c|}{396.880} & \multicolumn{2}{|c|}{1.034 .127} \\
\hline Alunos analisados & \multicolumn{2}{|c|}{461.241} & \multicolumn{2}{|c|}{160.321} & \multicolumn{2}{|c|}{395.477} & \multicolumn{2}{|c|}{1.017 .039} \\
\hline Cota racial & 4.630 & $(1 \%)$ & 2.070 & $(1,3 \%)$ & 6.447 & $(1,6 \%)$ & 13.147 & $(1,3 \%)$ \\
\hline Cota social & 4.2194 & $(9,1 \%)$ & 1.4753 & $(9,2 \%)$ & 4.3524 & $(11 \%)$ & 10.0471 & $(9,9 \%)$ \\
\hline Cota (outro) & 30.401 & $(6,6 \%)$ & 8.113 & $(5,1 \%)$ & 24.749 & $(6,3 \%)$ & 63.263 & $(6,2 \%)$ \\
\hline Total cotas & 77.225 & $(16,7 \%)$ & 24.936 & $(15,6 \%)$ & 74.720 & $(18,9 \%)$ & 176.881 & $(17,4 \%)$ \\
\hline ProUni & 45.354 & $(9,8 \%)$ & 11.781 & $(7,3 \%)$ & 25.442 & $(6,4 \%)$ & 82.577 & $(8,1 \%)$ \\
\hline Fies & 17.724 & $(3,8 \%)$ & 18.945 & $(11,8 \%)$ & 34.721 & $(8,8 \%)$ & 71.390 & $(7,0 \%)$ \\
\hline Classes & & & & & & & & \\
\hline Cursos & & & & & & & & \\
\hline
\end{tabular}

As colunas se referem aos anos do Enade. A linha Dados originais indica a quantidade de alunos nos respectivos Enades. Alunos analisados informa a quantidade de alunos após a remoção dos registros com dados faltantes (cf. texto). Cota racial indica o número de alunos que declararam ter sido admitidos por critério racial - o número entre parênteses indica a proporção em relação ao número de alunos analisados. Cota social se referee ao número de alunos que foram admitidos por critério social (respostas c) e d) - cf. texto). Cota (outro) informa o número de alunos que foram admitidos por uma combinação de critérios. ProUni, alunos que receberam bolsa do ProUni. Fies, alunos que receberam financiamento pelo Fies. Classes indica o número de diferentes classes no banco de dados, e Cursos, o número de cursos diferentes.

Fonte: Dados do Enade 2012 a 2014 processados pelos autores.

A Tabela 1 apresenta as proporções de alunos com algum benefício, em relação ao número total de alunos analisados. A linha Classes indica o número de classes (segundo a nossa definição - cf. abaixo) incluídas nos exames. Curso é o numero de cursos/carreiras que fizeram o exame naquele ano.

Um outro número interessante é a proporção de alunos com benefícios entre seus colegas de classe. Essa proporção é uma aproximação da proporção de alunos com benefícios em relação a todos os outros alunos que poderiam tê-lo recebido; por exemplo, alunos de IES não pagas não são elegíveis para ter empréstimos via Fies, portanto, não poderiam receber o benefício. A Tabela 2 reporta essas proporções 
Tabela 2 - Proporção de alunos com algum benefício apenas em relação ao total de seus colegas de classe

\begin{tabular}{ccccc}
\hline & 2012 & 2013 & 2014 & Total \\
\hline Cota racial & $1,9 \%$ & $3,0 \%$ & $3,4 \%$ & $2,6 \%$ \\
Cota social & $10,0 \%$ & $10,7 \%$ & $11,9 \%$ & $10,8 \%$ \\
Cota (outro) & $6,6 \%$ & $5,1 \%$ & $6,2 \%$ & $6,2 \%$ \\
Total cotas & $15,9 \%$ & $14,4 \%$ & $17,4 \%$ & $16,3 \%$ \\
ProUni & $13,8 \%$ & $11,1 \%$ & $9,1 \%$ & $11,9 \%$ \\
Fies & $3,9 \%$ & $12,2 \%$ & $9,9 \%$ & $7,5 \%$ \\
\hline
\end{tabular}

Fonte: Dados do Enade processados pelos autores.

\section{Metodologia}

0 primeiro ponto importante da metodologia é que quisemos uma análise que fosse independente do curso. Obtivemos isso padronizando as notas dos exames específicos por curso, isto é, subtraindo de cada nota a média das notas para aquele curso, e dividindo o resultado pelo desvio padrão das notas do curso. Ou seja, zic $=(y i c-\operatorname{média}(y j c)) /$ desvio padrão(yjc), sendo que yic é a nota no exame específico do aluno $i$, que está no curso c; zic é a nota transformada do aluno, média(yjc) é a média das notas para todos os alunos do curso c, e desvio padrão (yjc) é o desvio padrão das notas dos alunos do curso $c$.

A nota transformada deve ser entendida como a nota acima da média do curso medida em desvios padrão. Se $z i=1,3$, então o aluno i tirou uma nota 1,3 desvios padrão acima da nota média no seu curso; se $z i=-0,7$, então o aluno tirou uma nota 0,7 desvios padrão abaixo da nota média do curso.

Como o exame geral é o mesmo a cada ano, a padronização da nota é calculada pela média e desvio padrão dos alunos que fizeram o Enade naquele ano.

Nas análises, faremos sempre a comparação entre o conjunto de notas transformadas dos alunos que se beneficiaram de alguma política de inclusão e o conjunto de notas transformadas dos alunos que não se beneficiaram de políticas e que estavam nas mesmas classes que os primeiros. Vamos indicar como zig a nota transformada do aluno $i$ que pertence a classe $g$, de modo que o conjunto das notas transformadas dos alunos beneficiados por uma política de inclusão $p$ é definido como: $B(p)=\{z i g$ tal que $i$ foi beneficiado pela política $p$ \}, e o conjunto de notas transformadas dos não beneficiados é definido como: $N B(p)=\{z i g$ tal que $i$ não foi beneficiado por $p$ e existe um aluno $j$ tal que $z j g \hat{I} B(p)\}$.

Note que, para que um aluno $i$ entre no conjunto $N B(p)$, requer-se que haja algum aluno naquela classe que tenha sido beneficiado pela política de inclusão (o aluno j na fórmula).

A necessidade de se comparar os alunos beneficiados com seus colegas de classe é importante, pois isso remove o viés relativo aos tipos diferentes de IES. Por exemplo, vamos assumir para efeito de argumentação que alunos de IES pagas têm, em média, resultados piores no Enade do que alunos de IES públicas e que políticas de cotas só existem em IES públicas. Como alunos cotistas estão em IES públicas, se formos compará-los como todos os alunos não cotistas, que incluiria também alunos de IES pagas, a nota média do segundo grupo seria provavelmente menor que a do primeiro. Selecionando não cotistas apenas de IES e cursos nos quais existem cotistas, eliminamos esse viés. Por outro lado, alunos que receberam o Fies, e que estão em IES pagas, teriam uma desvantagem injusta quando comparados com todos os alunos de IES públicas, já que estes com certeza não receberam o Fies.

A comparação entre o conjunto de notas transformadas de beneficiários e de não beneficiários que estavam nas mesmas classes é feita por meio de duas medidas. A primeira é apenas a diferença da média dos dois conjuntos, que chamaremos de ganho padronizado dos alunos beneficiados pela política: ganho $(p)=$ $\operatorname{media}(B(p))$ - media $(N B(p))$.

Um ganho de 1,3 para alunos cotistas, por exemplo, indica que a média das notas do 
cotistas está 1,3 desvios padrão acima da média dos não cotistas; um ganho de $-0,7$ para alunos do Fies indica que a média das notas dos alunos com empréstimo pelo Fies é 0,7 desvios padrão abaixo da nota dos alunos sem empréstimos.

A segunda medida de comparação é o d de Cohen, que é a mais comum em educação. $0 \mathrm{~d}$ de Cohen é a diferença entre as médias das notas transformadas, mas divididas pelo desvio padrão dos dois grupos (mais precisamente, o desvio padrão dos dois grupos é a raiz quadrada da média ponderada da variância dos dois grupos).

Note que, a não ser que um grupo tenha um desvio padrão muito diferente do outro, o $\mathrm{d}$ de Cohen não deve ser numericamente muito diferente do ganho padronizado, já que o desvio padrão para todas as notas transformadas (para todos os alunos) é 1 .

\section{A definição de uma classe}

Neste artigo, uma classe é a combinação de valores para curso, município, período de aula e IES de um aluno. Assim, assume-se que todos os alunos do período noturno do curso A, da IES B na cidade C são colegas de classe, e serão pareados com seus colegas que receberam algum benefício de uma política de inclusão.

Nos dados do Enade 2012-2014, essa definição de classe resulta em 22.689 classes diferentes, com em média 44,83 alunos por classe (mediana $=27$ alunos). Há 213 classes com mais de trezentos alunos (até o máximo de 9.689 alunos numa mesma classe). Acreditamos que há duas explicações para essas classes numerosas: elas podem representar cursos de grandes IES privadas que são oferecidos em vários campi da mesma cidade, ou representam cursos a distância. Infelizmente os dados do Enade não nos permitem distinguir entre essas duas alternativas. Consideraremos que as classes mais numerosas não são um problema para a análise, pois, no caso dos cursos a distância, os alunos são efetivamente da mesma classe e, nos casos de cursos distribuídos em uma metrópole, as técnicas pedagógicas, os planos de aula e possivelmente os professores são os mesmos nos diferentes campi.

\section{Análise estatística e limite de equivalência prática}

Como mencionamos, a grande maioria dos estudos publicados sobre rendimento não faz a nenhuma análise estatística dos resultados. Verificar se as diferenças encontradas são estatisticamente significativas é um passo fundamental para entender se elas são grandes o suficiente para que não tenham surgido apenas por acaso ou, mais formalmente, devido a um erro amostral. Neste artigo, faremos tal análise, mas em vez de usar o mais tradicional p-valor para mostrar que as diferenças são (ou não) significativas, usaremos intervalos de confiança na medida de ganho padronizado. Os intervalos de confiança serão calculados usando $t$ de Student, com 95\% de confiança. Se o intervalo de confiança para a diferença inclui o zero, então as diferenças não são estatisticamente significativas.

Contudo, entendimentos mais modernos sobre inferência estatística indicam que apenas a análise de significância estatística não é suficiente. É preciso defınir um limite para o qual as diferenças, mesmo que sejam estatisticamente significativas, não tenham consequência prática. Em particular, devido à quantidade de dados (veja Tabela 1), quase todas as diferenças serão estatisticamente significativas, mas, mesmo assim, algumas diferenças serão muito pequenas para serem relevantes do ponto de vista educacional. Lembramos que dois dos artigos analisados (VELLOSO, 2009; GARCIA; JESUS, 2015) propõem algo similar, isto é, um limite abaixo do qual as diferenças entre os dois grupos sejam consideradas irrelevantes, ou seja, os grupos são considerados equivalentes.

Neste artigo, definiremos tal limite de irrelevância ou equivalência usando a medida de ganho padronizado. Definimos como o limite de equivalência o ganho padronizado dos alunos que estão no grupo com nota até 5\% abaixo da 
média e daqueles que estão no grupo com nota até 5\% acima da média. Ou seja, se dividirmos os alunos em vinte grupos de mesmo tamanho, baseado na nota transformada, a menor diferença que consideraremos como importante ou relevante é a diferença na média dos alunos que estão no grupo imediatamente acima e imediatamente abaixo da média. A ideia é que a diferença entre esses dois grupos é a menor diferença entre quaisquer dos 20 grupos (já que as notas estão distribuídas normalmente e esses dois grupos estão imediatamente em volta da média), e essa é a menor diferença relevante.

Infelizmente, essa construção não nos permite definir um limite de equivalência para o d de Cohen, o qual mede a separação na distribuição entre as medidas de dois grupos. $\mathrm{Na}$ nossa construção, os grupos logo abaixo e logo acima da média estão separados, embora a distância das duas médias entre eles seja pequena (e essa é a nossa definição de uma diferença pequena), os grupos estão separados já que não há intersecção entre eles. Dessa forma, não faremos a análise de equivalência para o d de Cohen.

\section{Reprodutibilidade dos resultados}

Os dados do Enade de 2012 a 2014 estão disponíveis no site do Inep (http:// portal.inep.gov.br/basica-levantamentosacessar). 0 programa (em R) para ler os dados e computar as análises estatísticas realizadas neste artigo está disponível em https://figshare.com/articles/Pol_ticas_de_ inclus_o_no_ensino_superior_avalia_o_ do_desempenho_dos_alunos_baseado_no_ ENADE_de_2012_a_2014/3180112.

\section{Resultados}

Limites de equivalência

De acordo com procedimento discutido na seção de metodologia, o limite de equivalência para o exame específico é 0,132 , e para o geral, 0,139 . Tendo em vista a proximidade dos dois limites, usaremos o menor dos valores $(0,132)$ como o limite de equivalência no restante deste artigo.

\section{Ganhos padronizados e $\mathrm{d}$ de Cohen para todos os benefícios}

A Tabela 3 reporta os valores do ganho padronizado, o intervalo de confiança para o ganho padronizado e o valor do d de Cohen para todas as comparações dos beneficiados por diferentes políticas de inclusão com seus colegas de classe que não foram beneficiados.

Tabela 3 - Resultados do ganho padronizado, intervalo de 95\% de confiança e d de Cohen para alunos com benefícios e seus colegas sem o benefícios.

\begin{tabular}{cccccc}
\hline Benefício & Exame & Ganho & \multicolumn{2}{c}{ IC $95 \%$} & d \\
\hline Cota & Específico & 0,04 & 0,04 & 0,05 & 0,04 \\
Cota & Geral & 0,01 & 0,01 & 0,02 & 0,01 \\
ProUni & Específico & $\mathbf{0 , 4 7}$ & $\mathbf{0 , 4 6}$ & $\mathbf{0 , 4 7}$ & 0,49 \\
ProUni & Geral & $\mathbf{0 , 4 1}$ & $\mathbf{0 , 4 1}$ & $\mathbf{0 , 4 2}$ & 0,43 \\
Fies & Específico & $-0,05$ & $-0,06$ & $-0,04$ & $-0,05$ \\
Fies & Geral & $\mathbf{0 , 0 1}$ & $\mathbf{0 , 0 0}$ & $\mathbf{0 , 0 2}$ & $\mathbf{0 , 0 1}$ \\
\hline
\end{tabular}

A primeira coluna indica o benefício; a segunda, o exame do Enade; a terceira, o ganho padronizado e o intervalo de 95\% de confiança; e a última, $0 \mathrm{~d}$ de Cohen. Em negrito os ganhos padronizados superiores ao limite de equivalência adotado neste artigo.

Fonte: Dados do Enade processados pelos autores.

Para cotas, a primeira linha se refere ao exame específico, a segunda ao exame geral. Note que os ganhos padronizados para os dois exames estão muito abaixo do que consideramos como o limite de equivalência. Portanto, não há diferença prática entre as notas de alunos que se beneficiaram da política de cotas e as de seus colegas de classe que não se beneficiaram dela.

Note também que o intervalo de confiança para o ganho padronizado em nenhum caso inclui o zero, o que significa que a diferença entre cotistas e não cotistas é estatisticamente significativa, o que era esperado, já que há um número muito grande de dados. 
Para alunos bolsistas do ProUni, nos dois exames, o um ganho padronizado é bem maior do que o limite de equivalência, a favor dos bolsistas. Ou seja, os alunos do ProUni tiveram em média notas maiores que seus colegas, tanto no exame geral quanto no específico. Essas diferenças são estatisticamente significativas (não são devidas à sorte) e são de importância prática na definição deste artigo. Finalmente, para alunos com empréstimo do Fies, também não há diferença prática entre eles e seus colegas sem empréstimo.

\section{Estudo aprofundado dos resultados de cotas}

Muito da literatura sobre o desempenho de alunos cotistas no Brasil faz distinção entre diferentes tipos de cursos e diferentes tipos de alunos cotistas. Gutterres (2015) separa alunos cotistas por razão racial, por razão de renda familiar e por razão de ter feito o segundo grau em escola pública. Vários autores, entre eles Queiroz e Santos (2006), Waltenberg e Carvalho (2012) e Silva e Pacheco (2013), separam os cursos entre os de maior e os de menor prestígio e de forma geral encontram que o desempenho dos cotistas nos cursos de maior prestígio é pior que o de não cotistas. Nesta seção vamos fazer esse tipo de análise mais aprofundada sobre o desempenho de alunos cotistas.

A Tabela 4 apresenta os resultados dos alunos separados pelo tipo de cota (racial e/ou social). Nesse caso, comparamos alunos que declaram ter ingressado por cota racial com alunos que não ingressaram por benefício de cotas, e da mesma forma para cotas sociais. Como mencionamos, uma das respostas à pergunta de cotas nos questionários é ambígua e pode indicar que o aluno recebeu uma cota por razões raciais ou por razões sociais. Portanto, fizemos duas análises para as cotas raciais e sociais, nas quais a resposta ambígua (combinação) está uniformemente incluída ou não em cada uma das duas categorias.
Tabela 4 - Análise dos diferentes tipos de cotas: raciais, ou sociais

\begin{tabular}{cccccc}
\hline Benefício & Exame & Ganho & IC 95\% & \multicolumn{2}{c}{ d } \\
\hline Raça & Específico & 0,03 & 0,01 & 0,05 & 0,03 \\
Raça & Geral & 0,02 & 0,00 & 0,04 & 0,02 \\
Raça + combinação & Específico & 0,08 & 0,07 & 0,09 & 0,08 \\
Raça + combinação & Geral & 0,04 & 0,04 & 0,05 & 0,04 \\
Social & Específico & 0,03 & 0,02 & 0,04 & 0,03 \\
Social & Geral & 0,01 & 0,00 & 0,01 & 0,01 \\
Social + combinação & Específico & 0,05 & 0,04 & 0,05 & 0,05 \\
Social + combinação & Geral & 0,02 & 0,01 & 0,02 & 0,02 \\
\hline
\end{tabular}

Veja texto para a explicação do termo combinação.

Fonte: Dados do Enade processados pelos autores.

Os resultados mostram que, para todas as diferentes formas de análise, não existe diferença prática entre os alunos cotistas e seus colegas não cotistas.

A Tabela 5 apresenta o ganho padronizado de alunos cotistas para as melhores classes. As melhores classes são os 10\% das classes com as maiores médias na nota específica. Entendemos que as classes com média alta representam combinações de cursos e IES de maior prestígio. Por exemplo, se o curso A da IES B é considerado muito bom e prestigioso, então esperamos que essa classe esteja entre os 10\% melhores no exame específico. Da mesma forma, se o curso C da IES D também é considerado muito bom, então ele também deve estar entre as 10\% melhores classes. Assim não fazemos distinção entre cursos de maior prestígio, mas sim entre combinações de curso e IES de maior prestígio. Entendemos que a separação de classes melhores captura em parte o fato de que devem haver combinações entre curso e IES que são mais competitivas e para as quais alunos cotistas talvez tenham um ganho padronizado pior. Mas não é isso que encontramos nos dados: o desempenho de alunos cotistas e não cotistas é equivalente para todos os efeitos práticos nas classes melhores. 
Tabela 5 - Análise da diferença entre cotistas e não cotistas nos $10 \%$ das classes com maiores médias no exame específico

\begin{tabular}{ccccc}
\hline Exame & Ganho & \multicolumn{2}{c}{ IC 95\% } & $d$ \\
\hline Específico & $-0,02$ & $-0,04$ & 0,00 & $-0,02$ \\
Geral & $-0,07$ & $-0,08$ & $-0,05$ & $-0,07$ \\
\hline
\end{tabular}

Fonte: Dados do Enade processados pelos autores.

\section{Discussão}

Acreditamos que esta pesquisa tem alguns pontos positivos importantes em relação às outras já publicadas. Em primeiro lugar, ela mede o rendimento de alunos ao final da graduação e, portanto, é uma melhor aproximação aos conhecimentos totais adquiridos pelo aluno durante o ensino superior e sua preparação para a futura carreira profissional. A grande maioria dos artigos publicados sobre rendimento de alunos cotistas mede o desempenho mais cedo durante o curso.

Outra característica importante é que os nossos resultados são agregados para todos os cursos, isto é, não calculamos as diferenças no rendimento de bolsistas e cotistas por curso. Acreditamos que uma análise por curso não avança o debate público sobre políticas de inclusão. Por exemplo, digamos que para o curso A, descobrimos que o ganho de cotistas é negativo e maior que o nosso limite de equivalência, ou seja, que, para todos os efeitos práticos, os cotistas têm um desempenho pior que os não cotistas. Por um lado, as políticas públicas não devem criar exceções para um curso e, nesse caso, propor que não haja cotas para o curso A. Por outro lado, uma IES não pode usar essa informação para criar mecanismos para um melhor acompanhamento a cotistas do curso A, pois os dados são globais, isto é, se referem a todos os cursos A de todas IES. A diferença no desempenho pode não ser verdadeira para uma IES em particular. Assim, as IES devem fazer suas próprias análises dos dados do Enade para verificar se um acompanhamento mais cuidadoso de cotistas ou bolsistas se faz necessário em algum dos seus cursos. A divulgação de que cotistas têm um desempenho menor que não cotistas para o curso A só criaria um constrangimento para os primeiros, sem fornecer nenhuma informação útil aos outros agentes envolvidos.

Nossos resultados, diferentemente de grande parte das análises já publicadas, se referem a estudantes amostrados de todo do Brasil e não apenas de uma ou outra IES e, portanto, devem ser mais generalizáveis (ver discussão sobre os limites da pesquisa mais abaixo).

Um outro importante aspecto desta pesquisa é que não estamos controlando os resultados por nível socioeconômico. Pesquisas baseadas no Enade, como as de Waltenberg e Carvalho (2012) e Pereira, Bittencourt e Braga (2015), modelam as notas dos alunos por meio de uma regressão que envolve muitas variáveis que descrevem o nível socioeconômico do aluno. Diz-se que essas pesquisas controlam pelo nível socioeconômico. Pela regressão, essas pesquisas criam um modelo de qual deveria ser a nota de um aluno tendo de vista as muitas variáveis e descobrem se o fato de o aluno ser cotista entra na equação com um coeficiente positivo, que indica que cotistas têm uma nota acima do que deveriam, ou se o coeficiente é negativo, que indica que ser cotista tem um efeito negativo na nota esperada. Nesta pesquisa não usamos ferramentas de regressão que permitem modelar uma nota esperada. Comparamos o conjunto das notas obtidas pelos cotistas, bolsistas e alunos que receberam empréstimos do Fies com o conjunto das notas de seus colegas de classe e, comparando as médias desses conjuntos, determinamos se cotistas de fato sabem tanto quanto seus colegas de classes. Do ponto de vista da avaliação de uma política pública, acreditamos que esta é a medida mais correta para o resto da sociedade: os alunos que se beneficiaram de uma política de inclusão não terminam do ensino superior como profissionais de menor qualidade.

0 mais importante limite na generalização desta pesquisa é quanto à validade do instrumento exame em si. 0 primeiro problema é 
que o Enade é um exame sem riscos ou benefícios para os alunos (low stake). A nota do Enade não tem impacto sobre a graduação do aluno ou sobre oportunidades futuras de emprego e, portanto, o aluno pode ir mal no exame, sem custo pessoal. Por outro lado, espera-se que em grandes números, o Enade corresponda em parte ao conhecimento adquirido pelos alunos, já que ele é uma parte importante da avaliação das instituições de ensino superior. Também podese argumentar que outros exames nacionais, por exemplo Pisa, Saeb e Prova Brasil (nas não o Enem) são exames sem risco ou benefícios e, no entanto, políticas de públicas e avaliações de escolas são feitas baseado nesses exames. Finalmente, embora a avaliação de rendimento baseada em CR pareça ser mais precisa, pode-se argumentar que o CR possui riscos e benefícios não lineares para os alunos e, portanto, não é um instrumento tão preciso. Para a grande maioria dos alunos uma nota menor que cinco traz o risco enorme de repetir na disciplina, mas notas maiores que cinco não trazem nenhum benefício (a não ser nos poucos casos em que o aluno compete com os colegas por uma bolsa de iniciação científica ou monitoria). Uma outra questão é se o Enade é um instrumento capaz de medir o conhecimento profissional de um formando nos diversos cursos. Essa questão, até onde sabemos, não foi verificada empiricamente, a não ser por uns poucos trabalhos que avaliam as características psicométricas de alguns exames específicos (PRIMI; HUTZ; SILVA, 2011; LOPES; VENDRAMINI, 2014; CAMARGO; CAMARGO; ANDRADE; BORNIA, 2016).

Quão surpreendentes são os resultados reportados neste artigo? A equivalência prática entre os resultados de cotistas e não cotistas parece concordante com parte da literatura mais antiga, que normalmente afirma uma equivalência entre os dois grupos, mas são menos rigorosas em mostrar essa equivalência (VELLOSO, 2009; QUEIROZ; SANTOS, 2006; TESSLER, 2006). Por outro lado, esta pesquisa é parcialmente conflitante com resultados mais recentes, que usam o Enade para computar resultados que não são limitados a uma só IES (WALTENBERG; CARVALHO, 2012; PEREIRA; BITTENCOURT; BRAGA, 2015). Mas a literatura mais recente faz uma análise separada por tipo de IES ou por curso, procedimento que não adotamos, pois não acreditamos que esses níveis de análise respondam a questões úteis sobre a política de cotas.

Quanto ao ProUni, nossos resultados concordam com os de Barbosa e Santos (2011). Mas não é difícil explicar o melhor desempenho de alunos do ProUni. Os critérios de concessão da bolsa não são claros no que tange à ordenação dos candidatos, mas é razoável assumir que a nota do Enem seja um componente importante e, portanto, é provável que alunos com bolsa ProUni são alunos com uma melhor formação ao final do segundo grau que seus colegas de classe. 0 ProUni ainda exige uma aprovação em pelo menos 75\% das disciplinas cursadas no semestre anterior, e isto talvez tenha um impacto positivo no desempenho do bolsista.

Finalmente, nossos resultados sobre o Fies são parcialmente conflitantes com os de Barbosa e Santos (2011). Elas apresentam dados de que alunos que receberam empréstimos via Fies têm um desempenho melhor do que alunos sem bolsas ou empréstimos, mas a análise das autoras inclui apenas alguns cursos.

\section{Conclusão}

Não há diferença prática entre o conhecimento de alunos cotistas e o de seus colegas de classes não cotistas ao final do curso, se assumirmos que o exame do Enade mede o tanto habilidades gerais de raciocínio como conhecimentos específicos do curso. Não há diferença prática entre o conhecimento de alunos cotistas por razões raciais ou sociais e o de seus colegas de classes que não são cotistas. Não há diferença prática de conhecimentos entre cotistas e não cotistas em classes com média alta nos exames de conhecimento específico. Também não há diferença prática de conhecimento ao final da graduação entre alunos que receberam empréstimo pelo Fies 
e seus colegas de classe que não receberam o empréstimo. Finalmente, alunos que receberam bolsa do ProUni parecem ter acumulado mais conhecimentos que seus colegas de classes.

Notamos que esses resultados, em particular no que se refere a políticas de cotas, se refere a uma situação anterior à lei 12.711; para os anos analisados, os cotistas totalizavam 17\% dos alunos. Notamos também que esses resultados se referem apenas a comparações de rendimento ao final do curso. Como discutimos, há outras medidas de interesse para políticas de inclusão: acesso, evasão e tempo de graduação, além do rendimento.

\section{Referências}

ALMEIDA, Cleide et al. Programa universidade para todos - ProUni - políticas públicas e inclusão social. Educação \& Linguagem, São Paulo, v. 13, n. 21, p. 67-88, 2010.

AMARAL, Daniela Patti do; OLIVEIRA, Fátima Bayma de. 0 Prouni e a conclusão do ensino superior: novas trajetórias pessoais e profissionais dos egressos. Ensaio: Avaliação e Políticas Públicas em Educação, Rio de Janeiro, v. 19, n. 73, p. 861-890, 2011.

BARBOSA, Maria Ligia de Oliveira; SANTOS, Clarissa Tagliari. A permeabilidade social das carreiras do ensino superior. Caderno CHR, Salvador. v. 24, n. 63, p. 535-554, 2011.

BERALDO, Antonio Fernando; MAGRONE, Eduardo. Política de cotas na Universidade Federal de Juiz de Fora: avaliação 2006-2011. In: SANTOS, Jocélio Teles dos (Ed.). 0 impacto das cotas nas universidades brasileiras (2004-2012). Salvador: CEA0, 2013. p. 105-136.

BEZERRA, Tereza Olinda Caminha; GURGEL, Claudio. A política pública de cotas em universidades, desempenho acadêmico e inclusão social. Sustainable Business International Journal, Rio de Janeiro, v. 9, p. 1-22, 2011.

CAMARGO, Raphael Vinicius Weigert; CAMARGO, Rita de Cássia Correa Pepinelli; ANDRADE, Dalton Francisco; BORNIA, Antonio Cezar. Desempenho dos alunos de ciências contábeis na prova ENADE/2012: uma aplicação da Teoria da Resposta ao Item. Revista de Educação e Pesquisa em Contabilidade (REPeC), Brasilia v. 10, n. 3, p. 332-355, 2016

CARVALHO, José Carmello. 0 ProUni como política de inclusão: estudo de campo sobre as dimensões institucionais e intersubjetivas da inclusão universitária, junto a 400 bolsistas no biênio 2005-2006. In: 30 Reunião anual da ANPEd. [S.I.: s.n.], 2008.

EURÍSTENES, Poema; CAMPOS, Luiz Augusto; FERES JÚNIOR, João. As políticas de ação afirmativa nas universidades estaduais (2015). [S.I.], 2015.

GARCIA, Francisco Augusto da Costa; JESUS, Girlene Ribeiro de. Uma avaliação do sistema de cotas raciais da universidade de Brasília. Estudos em Avaliação Educacional, São Paulo, v. 26, n. 61, p. 146-165, 2015.

GUTTERRES, Rafael dos Santos. Alunos que ingressaram no ensino superior por ações afirmativas apresentam melhor desempenho? Uma análise empregando a decomposição de Oaxaca para o ENADE 2012. Dissertação (Mestrado) - Faculdade de Administração, Contabilidade e Economia, Pontifícia Universidade Católica do Rio Grande do Sul, 2015.

MENDES JUNIOR, Alvaro Alberto Ferreira; WALTENBERG, Fábio Domingues. Políticas de cotas não raciais aumentam a admissão de pretos e pardos na universidade? Simulações para a UERJ. Planejamento e Políticas Públicas, Brasília, v. 44, p. 229-256, 2015.

MENDES JUNIOR, Alvaro Alberto Ferreira. Uma análise da progressão dos alunos cotistas sob a primeira ação afirmativa brasileira no ensino superior: o caso da universidade do estado do rio de janeiro. Revista Ensaio: Avaliação e Políticas Públicas em Educação, Rio de Janeiro, v. 22, n. 82, p. 31-56, 2014.

FERES JÚNIOR, João; DAFLON, Verônica Toste. Políticas da igualdade racial no ensino superior. Cadernos do Desenvolvimento Fluminense, Rio de Janeiro, v. 5, p. 31-43, 2014.

KIRK, Roger E. Practical significance: A concept whose time has come. Educational and psychological measurement, v. 56, n. 5, p. 746-759, 1996.

LOPES, Fernanda Luiza; VENDRAMINI, Claudette Maria Medeiros. Propriedades psicométricas das provas de pedagogia do ENADE via TRI. Avaliação: Revista da Avaliação da Educação Superior, Campinas, v. 20, n. 1, p. 27-47, 2014. 
NEVES, Paulo Sérgio da Costa. A política de reserva de vagas da universidade federal de Sergipe para alunos de escolas públicas e não brancos: uma avaliação preliminar. In: SANTOS, Jocélio Teles dos (Ed.). 0 impacto das cotas nas universidades brasileiras (2004-2012). Salvador: CEA0, 2013. p. 243-278.

PEREIRA, Joaquim Israel Ribas; BITTENCOURT, Mauricio; BRAGA, Bernardo. Affirmative action in higher education: Impacts of the national exam in Brazil. In: 55th Congress of the European Regional Science Association: World Renaissance: Changing roles for people and places. [S.I.: s.n.], 2015.

PINTO, Paulo Gabriel Hilu da Rocha. Ação afirmativa, fronteiras raciais e identidades acadêmicas: uma etnografia das cotas para negros na Uerj. In: ZONINSEIN, Jonas; FERES JÚNIOR, João (Org.). Ação afirmativa e universidade: experiências nacionais comparadas. Brasília: Editora da Universidade de Brasília, 2006.

PRIMI, Ricardo; HUTZ, Claudio Simon; SILVA, Marjorie Cristina Rocha da. A prova do ENADE de psicologia 2006: concepção, construção e análise psicométrica da prova. Avaliação Psicológica: Interamerican Journal of Psychological Assessment, Itatiba, v. 10, n. 3, p. 271-294, 2011.

QUEIROZ, Delcele Mascarenhas; SANTOS, Jocélio Teles dos. Sistema de cotas: um debate dos dados à manutenção de privilégios e de poder. Educação e Sociedade, Campinas, v. 27, n. 96, p. 717-737, 2006.

ROSSETTO, Cristina B. de Souza; GONÇALVES, Flávio de Oliveira. Equidade na educação superior no Brasil: Uma análise multinomial das políticas públicas de acesso. DADOS - Revista de Ciências Sociais, Rio de Janeiro, v. 58, n. 3, p. 791-824, 2015.

SANTOS, Jocélio Teles dos; QUEIROZ, Delcele Mascarenhas. 0 impacto das cotas na universidade federal da Bahia (2004-2012). In: SANTOS, Jocélio Teles dos (Ed.). 0 impacto das cotas nas universidades brasileiras (2004-2012). Salvador: CEA0, 2013. p. 37-66, 2013.

SARAIVA, Luiz Alex Saraiva; NUNES, Adriana de Souza. A efetividade de programas sociais de acesso à educação superior: 0 caso do ProUni. Revista de Administração Pública, Rio de Janeiro, v. 45, n. 4, p. 941-965, 2011.

SILVA, Maria Nilza da; PACHECO, Jairo Queiroz. As cotas na universidade estadual de londrina: balanço e perspectivas. In: SANTOS, Jocélio Teles dos (Ed.). 0 impacto das cotas nas universidades brasileiras (2004-2012). Salvador: CEA0, 2013. p. 67-104.

SILVEIRA, Paulo Roberto Cardoso da; SILVEIRA, Marta Íris Camargo Messias da; MESSIAS, Andressa Rodrigues. Monitoramento, permanência e promoção da diversidade: as ações afirmativas em risco na Universidade Federal de Santa Maria. In: SANTOS, Jocélio Teles dos (Ed.). 0 impacto das cotas nas universidades brasileiras (2004-2012). Salvador: CEA0, 2013. p. $171-202$.

TESSLER, Leandro R. Ação afirmativa sem cotas: 0 Programa de Ação Afirmativa e Inclusão Social da Unicamp. [S.I.], 2006.

TRAGTENBERG, Marcelo Henrique Romano et al. Impacto das ações afirmativas na universidade federal de Santa Catarina (2008-2011). In: SANTOS, Jocélio Teles dos (Ed.). 0 impacto das cotas nas universidades brasileiras (2004-2012). Salvador: CEA0, 2013. p. $203-242$.

VELLOSO, Jacques. Cotistas e não-cotistas: rendimento de alunos da Universidade de Brasília. Cadernos de Pesquisa, São Paulo, v. 39, n. 137, p. 621-644, 2009.

WALTENBERG, Fábio; CARVALHO Márcia. Cotas aumentam a diversidade dos estudantes sem comprometer o desempenho? Sinais Sociais, Rio de Janeiro, v. 7, n. 20, p. 36-77, 2012.

Recebido em: 20.04.2016

Aprovado em: 13.09.2016

Jacques Wainer é professor titular do Instituto de Computação da Unicamp. Ele tem PhD em Ciência da Computação pela Pennsylvania State University e atua em várias áreas da computação incluindo impactos sociais da computação. Sua pesquisa em educação foi publicada em Educação e Sociedade, Computers \& Education, e Higher Education.

Tatiana Melguizo é professora associada da Rossier School of Education, University of Southern California. Ela tem PhD em Economia da Educação pela Stanford University e mestrado em Políticas Sociais pela London School of Economics. Ela atua principalmente na área de Economia da Educação Superior. Sua pesquisa em educação foi publicada em Education Evaluation and Policy Analysis, The Journal of Higher Education, The Review of Higher Education, Research in Higher Education e Higher Education. 